\title{
Caracterización química y sensorial del aroma del calamar del genero Illex Argentinus.
}

\author{
V. Carrascón, R. López, A. Escudero \\ Laboratorio de Análisis de Aroma y Enología (LAAE) \\ Instituto de Investigación en Ingeniería de Aragón (I3A) \\ Departamento de Química Analítica. Facultad de Ciencias. \\ Pedro Cerbuna 12, 50009, Zaragoza, Spain, ,e-mail: vcarrasc@unizar.es
}

\begin{abstract}
El calamar es un cefalópodo ampliamente consumido en todo el mundo. El conocer los compuestos químicos responsables del olor de un alimento es lo que se denomina caracterización aromática. En este trabajo se estudió la caracterización química del aroma del calamar del género Illex Argentinus después de su cocinado. Los componentes volátiles del caldo de calamar fueron aislados utilizando distintas técnicas de extracción según el objetivo deseado. En primer lugar se obtuvo un extracto representativo del aroma mediante un sistema de espacio de cabeza dinámico para encontrar los compuestos más importantes en el aroma del calamar. Después, para la identificación, se emplearon la extracción en fase sólida (SPE) y un sistema de purga y trampa para conseguir una mayor recuperación de las moléculas odorantes. Se localizaron las zonas de olor más importantes mediante cromatografía de gases acoplada a un detector olfatométrico (GC-O) con un panel de 8 jueces entrenados (sniffers). Las moléculas responsables de esos aromas fueron identificadas, no sólo por su olor característico, si no también mediante índices de retención lineal, utilizando un detector de espectrometría de masas (GC-MS) y cromatografía de gases multidimensional (GC-GC-MS). Los compuestos identificados hasta el momento son la 2-acetilpirrolina (tostado), el metional (patata cocida), la 2-acetilpirazina (quemado), el 4,5-dimetiltiazol (verde), el furaneol (dulce), el ácido isovalérico (queso, rancio) y el ácido butírico (queso, vómito).
\end{abstract}

